\title{
Performance Analysis and Simulation of Wind Turbine Using Doubly fed Induction Generators for Various Voltage Sags at Grid
}

\author{
Abishek Naithani ${ }^{1}$ and Sandeep Thakur ${ }^{2}$ \\ ${ }^{1}$ Dept. of Electrical Engineering, ISM Dhanbad, Jharkhand \\ ${ }^{2}$ Dept. of Electronics and Telecommunication, MGMCET Kamothe, Navi Mumbai, \\ India \\ 1'abhinaithani@gmail.com, ${ }^{2}$ Sandeepatism@gmail.com
}

\begin{abstract}
Doubly fed Induction generators are used commonly in variable speed wind energy conversion systems due to their high output energy. This paper analyzes the steady state of wind power systems based on doubly-fed induction generator when subjected to different voltage sags at grid and the various parameters undergoing variations due to this. PWM converters are used as excitation power supply source to the DFIG wind energy conversion system of VSCF, which join rotor to the used grid. To control the convertor rotor side, vector control scheme is used which is based on stator voltage strategy. The model based on this scheme is simulated with the help of MATLAB software.
\end{abstract}

Keywords: Vector control; VSCF; DFIG;DC link voltage; back-to-back PWM converter

\section{Introduction}

As all the countries are facing scarcity of energy, Wind energy has seen a large surge in various fields. Particularly, grid-connected renewable sources plays major role in the development $[1,7]$. As the Penetration of wind turbine is increasing, the wind turbines are required to remain connected during the fault and contribute to stability of the system. The variable speed system, which utilizes wind energy, is the main type of grid-connected wind generation system [8-11]. So, it is necessary to learn how to control the gridconnected operation of variable-speed wind generation system and the various effects which happen when there is some disturbance in the grid .DFIG based wind generation is the main emergent technology of wind power generation at present. There are various advantages of DFIG like higher efficiency, separate controlling of Active and Reactive power etc.

\section{Operational Principle of Variable Speed Constant Frequency}

According to the principle of $\mathrm{AC}$ induction generator, the subsequent relations can be obtained as [2].

$$
f_{s}=\frac{n p}{60} \pm f_{r}
$$

The AC-excited VSCF wind power generation is shown in Error! Reference source not found..The system consists of a wind turbine system, DFIG, PWM converters, threephase transformer and the grid. If speed of rotor is less than the speed of stator then the system operates at sub-synchronous state, in such case AC excitation to the rotor of DFIG is given by inverter, and grid power is supplied by stator. If speed of rotor is greater than 
the speed of stator then the system runs at a super-synchronous state, and flow of power through the converter is reversed, now grid power is supplied by both stator as well as rotor. Therefore, it can be established that, if the DFIG speed changes, the stator frequency can be always maintained equal to the frequency of grid by changing the rotor frequency.

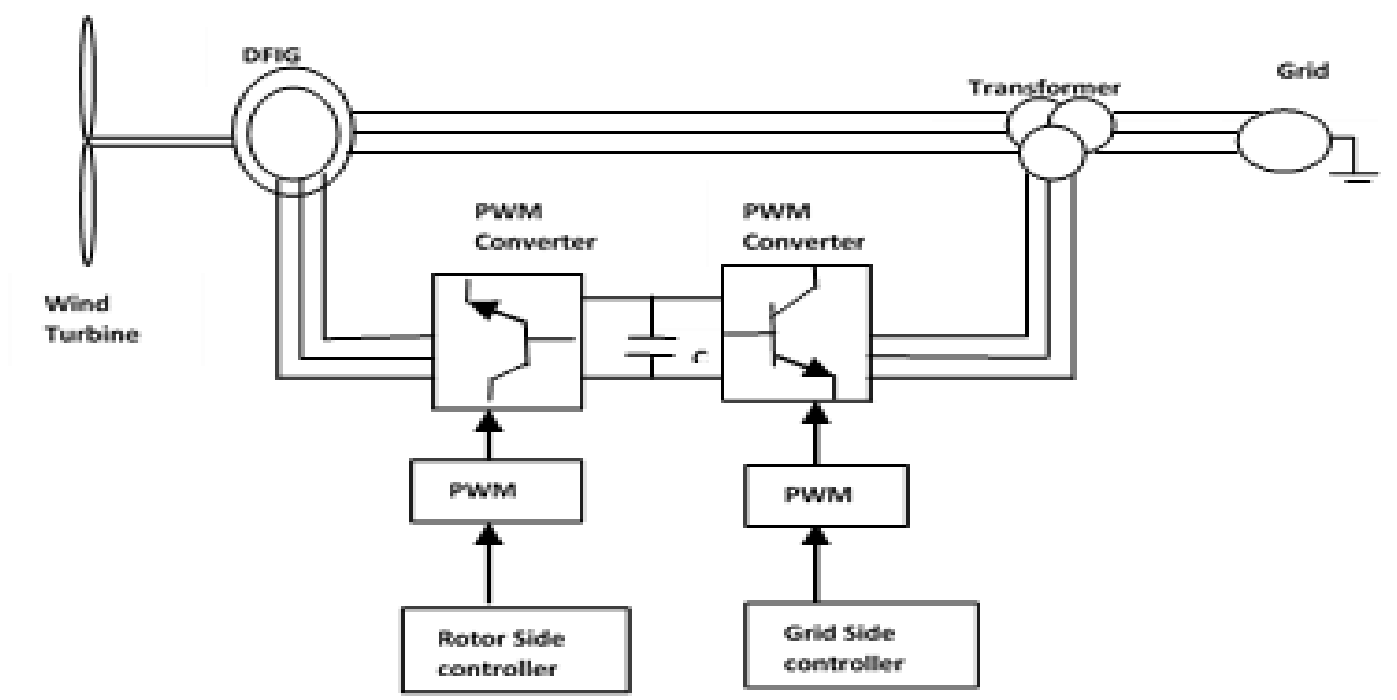

Figure 1. Diagram of DFIG based WECS

\section{Control Strategy}

As the stator of DFIG is connected directly to the grid therefore the frequency and magnitude of stator voltage can be considered as constant. So DFIG commonly adopts stator voltage oriented control strategy which is shown in Figure 2. Here $d$-axis is aligned with the stator voltage, therefore $V_{s}=V_{d s}$ and $V_{q s}=0$. The corresponding circuit of DFIG is represented in Figure 2.

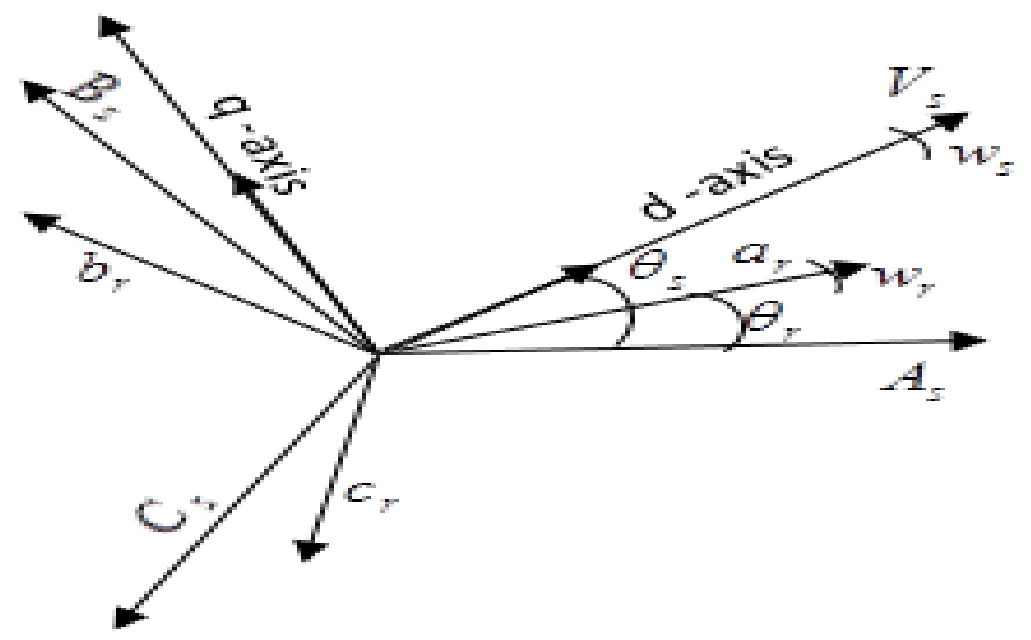

Figure 1(a). Stator Voltage Field Orientation Control Reference Frame

Also, the stator resistance is very less than winding reactance, therefore it can be ignored. 


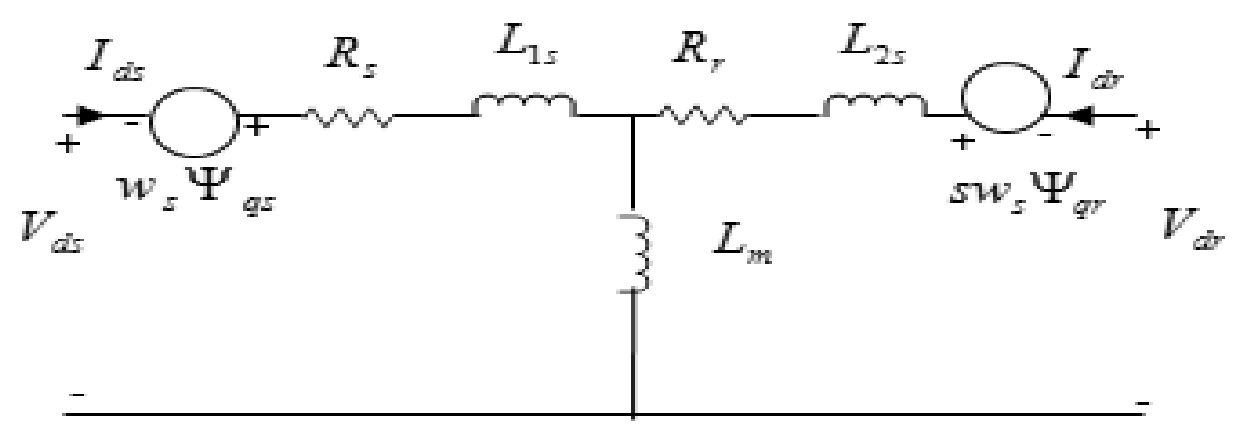

(a) $d$-axis

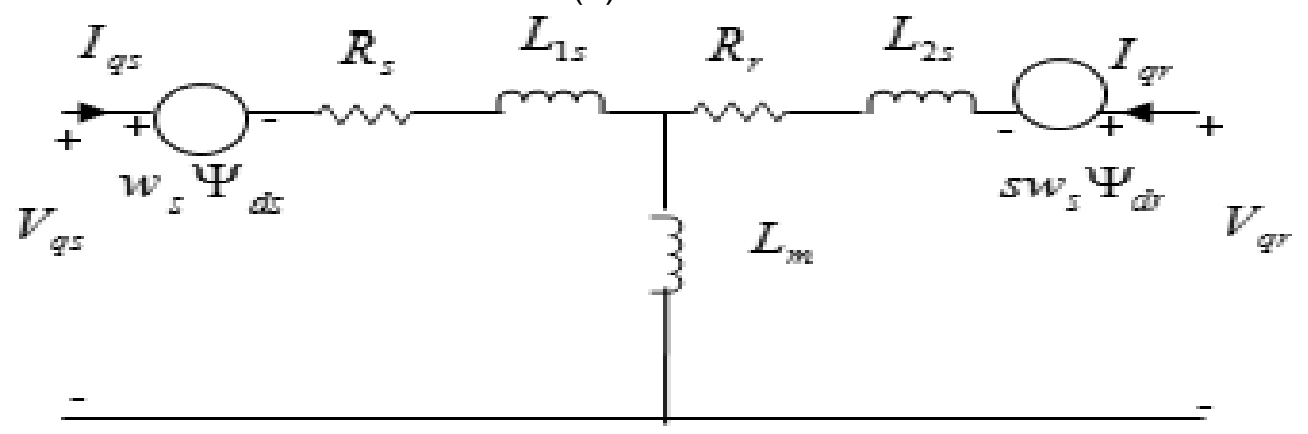

(b) $q$-axis

Figure 2. DFIG Equivalent Circuit (a) \& (b)

The following equations of voltages, flux linkages and Torque of DFIG is obtained [3]

[6] [7]: $\quad V_{d s}=R_{s} I_{d s}-w_{s} \psi_{q s}+\frac{d \psi_{d s}}{d t}$

$V_{q s}=R_{s} I_{q s}+w_{s} \psi_{d s}+\frac{d \psi_{q s}}{d t}$

$V_{d r}=R_{r} I_{d r}-s w_{s} \psi_{q r}+\frac{d \psi_{d r}}{d t}$

$V_{q r}=R_{r} I_{q r}+s w_{s} \psi_{d r}+\frac{d \psi_{q r}}{d t}$

$\psi_{d s}=L_{s} I_{d s}+L_{m} I_{d r}$

$\psi_{q s}=L_{s} I_{q s}+L_{m} I_{q r}$

$\psi_{d r}=L_{r} I_{d r}+L_{m} I_{d s}$

$\psi_{q r}=L_{r} I_{q r}+L_{m} I_{q s}$

$T_{e}=\frac{3}{2} n_{p}\left(\psi_{d s} I_{q s}-\psi_{q s} I_{d s}\right)$

Where $L_{s}=L_{1 s}+L_{m}, L_{r}=L_{1 r}+L_{m}, s w_{s}=w_{s}-w_{r}$

$T_{e}$ is electromagnetic torque; $n_{p}, L_{m}, \mathrm{~J}$ are number of pairs of poles, mutual inductance of generator, and coefficient of inertia respectively. The control system has two types of control: 


\section{A) Rotor side Converter Control}

The stator flux can be obtained from equation (2) and equation (3) by neglecting derivative part.

$$
\begin{aligned}
& \psi_{d s}=\left(V_{q s}-R_{s} I_{q s}\right) / w_{s} \\
& \psi_{q s}=\left(V_{d s}-R_{s} I_{d s}\right) /\left(-w_{s}\right) \\
& \psi_{s}=\sqrt{\psi_{d s}^{2}+\psi_{q s}^{2}}
\end{aligned}
$$

In rotor side controller $P_{\text {ref }}$ is compared with $P_{\text {meas }}$ whose output is fed into the PI controller to obtain $I_{d r_{-} r e f} . I_{d r_{-} r e f}$ is compared with $I_{d r}$ and output is fed into the PI controller to acquire the current regulation part $V_{d r}^{1} . V_{d r}^{1}$ is compared with cross coupling part $V_{d r}^{2}$ to obtain $V_{d r c}$. Similarly $V_{q r c}$ is obtained .Both $V_{d r c}$ and $V_{q r c}$ are then fed into the dq/abc converter and then into PWM to obtain RSC pulse. $V_{d r}^{2}$ and $V_{q r}^{2}$ are obtained based on (4) and (9), as:

$$
\begin{aligned}
& V_{d r}^{2}=R_{r} I_{d r}-s w_{s}\left(L_{r} I_{q r}+L_{m} I_{q s}\right) \\
& V_{q r}^{2}=R_{r} I_{q r}+s w_{s}\left(L_{r} I_{d r}+L_{m} I_{d s}\right)
\end{aligned}
$$

Finally $V_{d r c}$ and $V_{q r c}$ is given by following equation [6]

$$
\begin{aligned}
& V_{d r c}=V_{d r}=V_{d r}^{1}+V_{d r}^{2} \\
& V_{q r c}=V_{q r}=V_{q r}^{1}+V_{q r}^{2}
\end{aligned}
$$

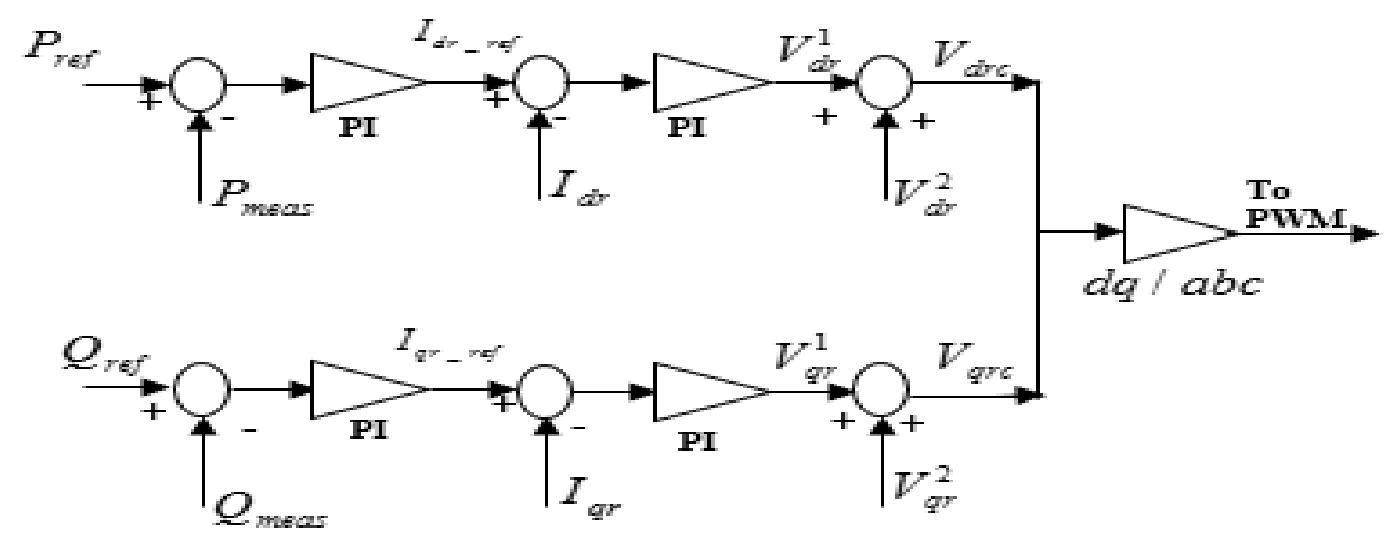

Figure 3. Rotor Side Controller

\section{B) Stator side Converter Control}

Stator side controller is used to maintain the DC link constant voltage. The stator side controller scheme is depicted in Figure 4.Here reference voltage $V_{d c_{-} \text {ref }}$ compared with measured voltage $V_{\text {meas }}$ whose output is fed into the PI controller to obtain $I_{d s c_{-} r e f} . I_{d s c_{-} r e f}$ is compared with $I_{d s c}$ and output is fed into the PI controller to obtain the current regulation part $V_{d c h}^{1}$.At last $V_{d s c}$ is obtained which is given by equation(22).

Similarly $V_{q s c}$ is obtained. Now both the signals are fed into the dq/abc converter and then into the PWM to obtain the GSC pulse. 
$V_{d s c}=V_{d s}-V_{d c h}$

$V_{q s c}=V_{q s}-V_{q c h}$

$V_{d c h}^{2}=R_{c} I_{d s c}-w_{s} L_{c} I_{q s c}$

$V_{q c h}^{2}=R_{c} I_{q s c}+w_{s} L_{c} I_{d s c}$

$V_{d s c}=V_{d s}-V_{d c h}^{1}-V_{d c h}^{2}$

$V_{q s c}=V_{q s}-V_{q c h}^{1}-V_{q c h}^{2}$

Here $s c$ represent stator-side converter and $c h$ represent choke.

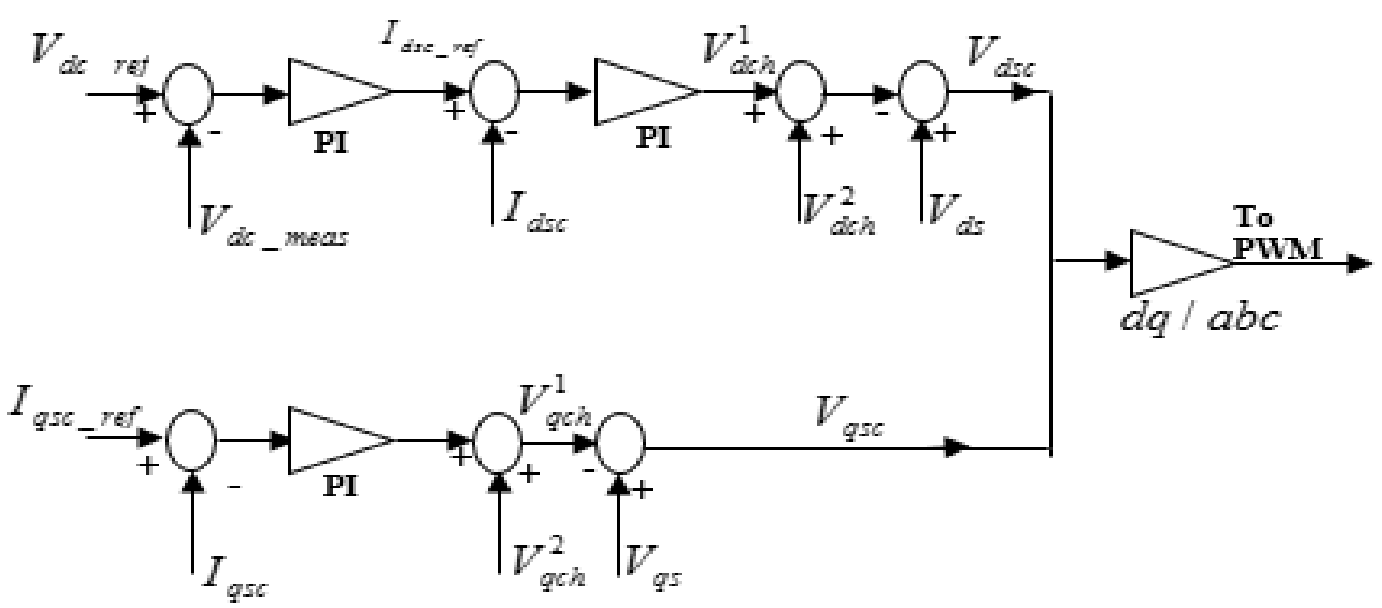

Figure 4. Stator Side Controller

\section{Simulation Analysis}

In order to verify the system, MATLAB2013 is used for simulating this model. The Simulation parameters of system are shown below.

Table 1. DFIG Parameters

\begin{tabular}{ll}
\hline \multicolumn{1}{c}{ Parameter } & \multicolumn{1}{c}{ Value } \\
\hline Nominal Wind speed & $12 \mathrm{~m} / \mathrm{s}$ \\
Nominal Apparent Power & $1.67 \mathrm{MVA}$ \\
Nominal Active Power & $1.5 \mathrm{MW}$ \\
Power Factor & 0.9 \\
Grid Voltage & $120 \mathrm{KV}$ \\
Grid Frequency & $60 \mathrm{~Hz}$ \\
Number of Poles & 6 \\
Nominal stator voltage & $575 \mathrm{~V}$ \\
Nominal rotor voltage & $1975 \mathrm{~V}$ \\
Stator Resistance & $0.023 \mathrm{p.u}$ \\
Stator Leakage Resistance & $0.18 \mathrm{p.u}$ \\
Referred Rotor Resistance & $0.016 \mathrm{p.u}$ \\
Referred Rotor Leakage Inductance & $0.156 \mathrm{p} . \mathrm{u}$
\end{tabular}


Stator to Grid coupling Resistance

Stator to Grid coupling Inductance

Mutual Inductance

Nominal DC link Voltage

DC link Capacitance
0.003 p.u

0.3 p.u

2.9 p.u

$1150 \mathrm{~V}$

$10 \mathrm{mF}$ 0.5 p.u

\section{Simulation Results}

Case (I) If the system is working in Normal condition

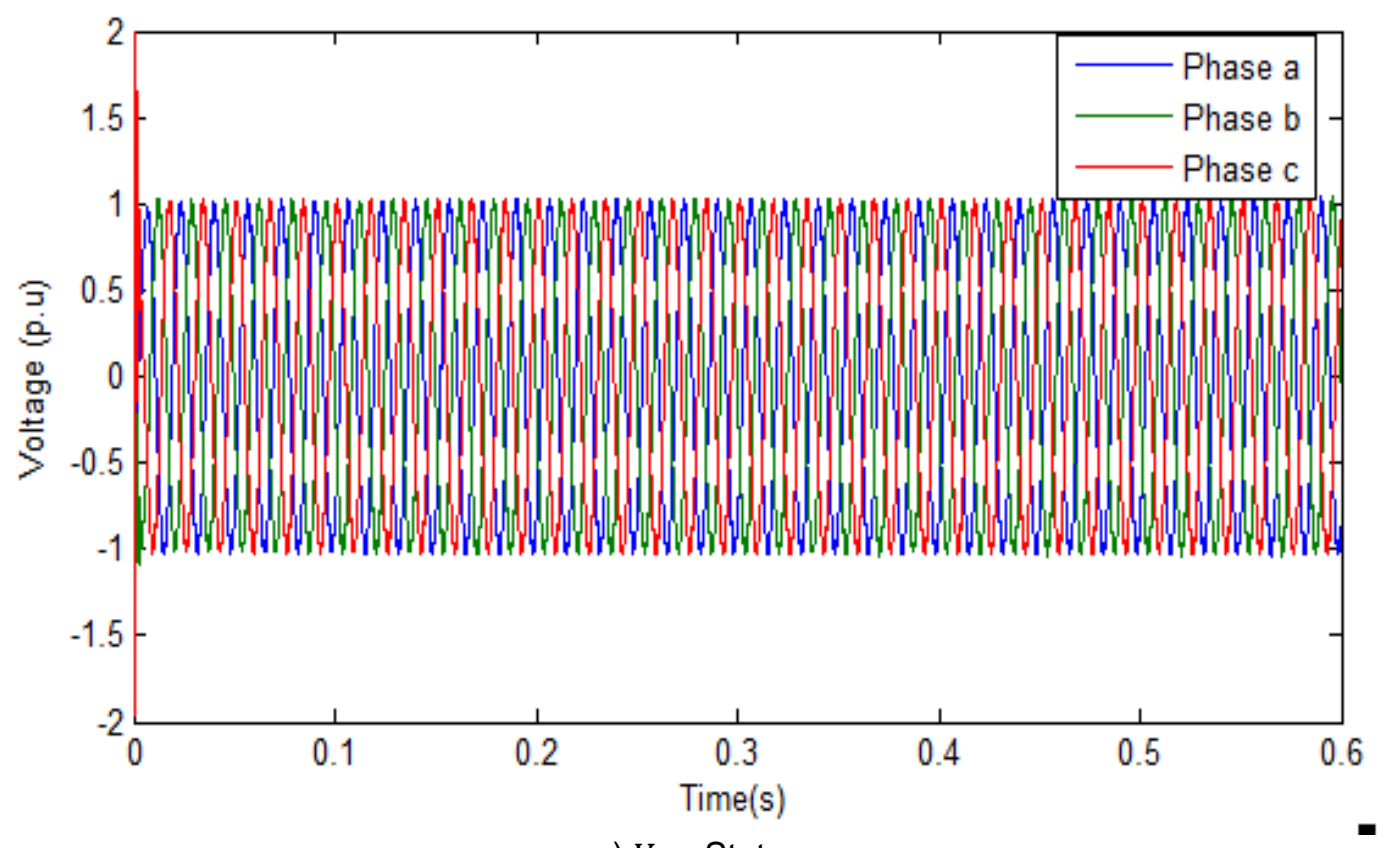

a) $V_{a b c}$ Stator 


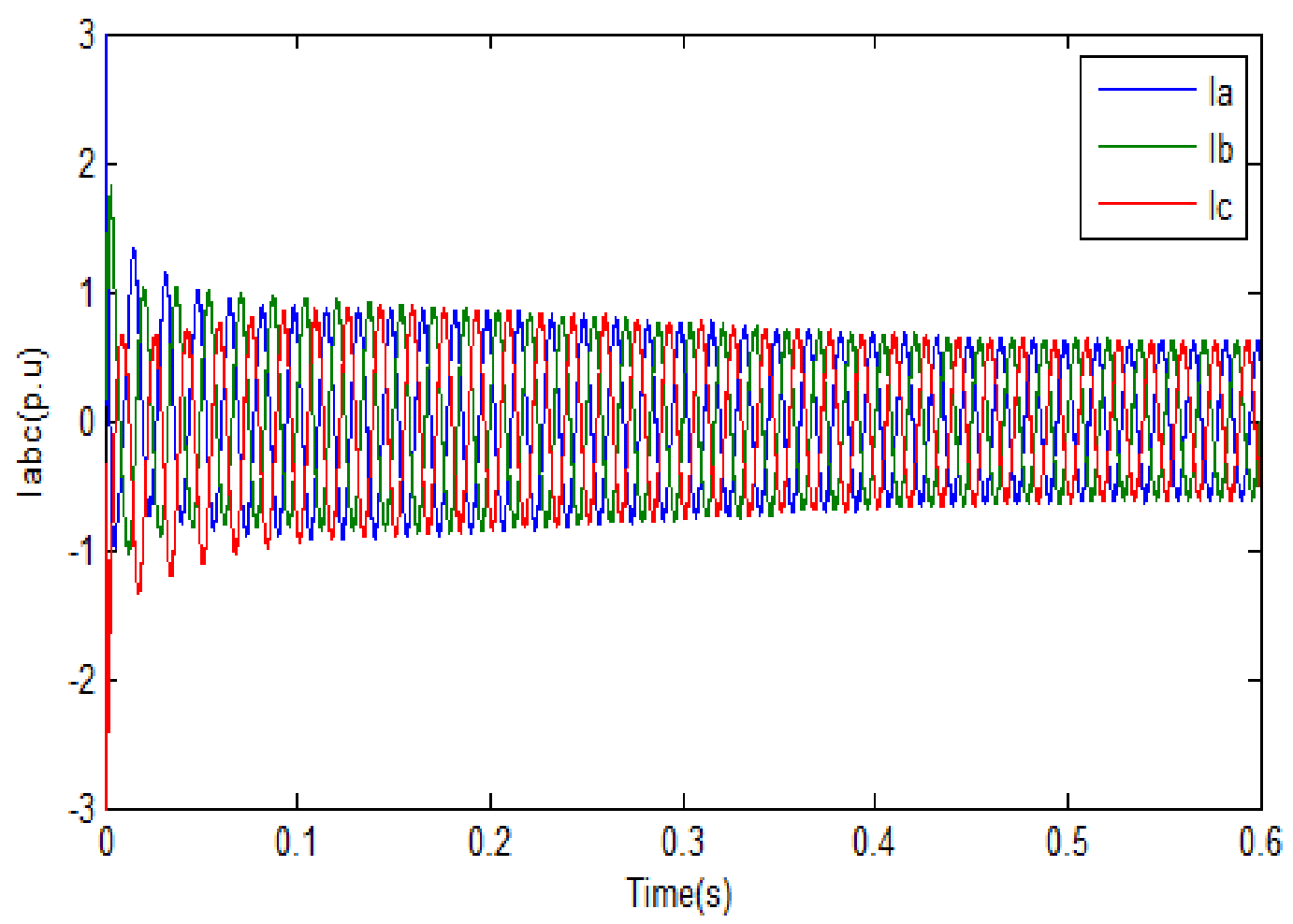

b) $I_{a b c}$ Stator

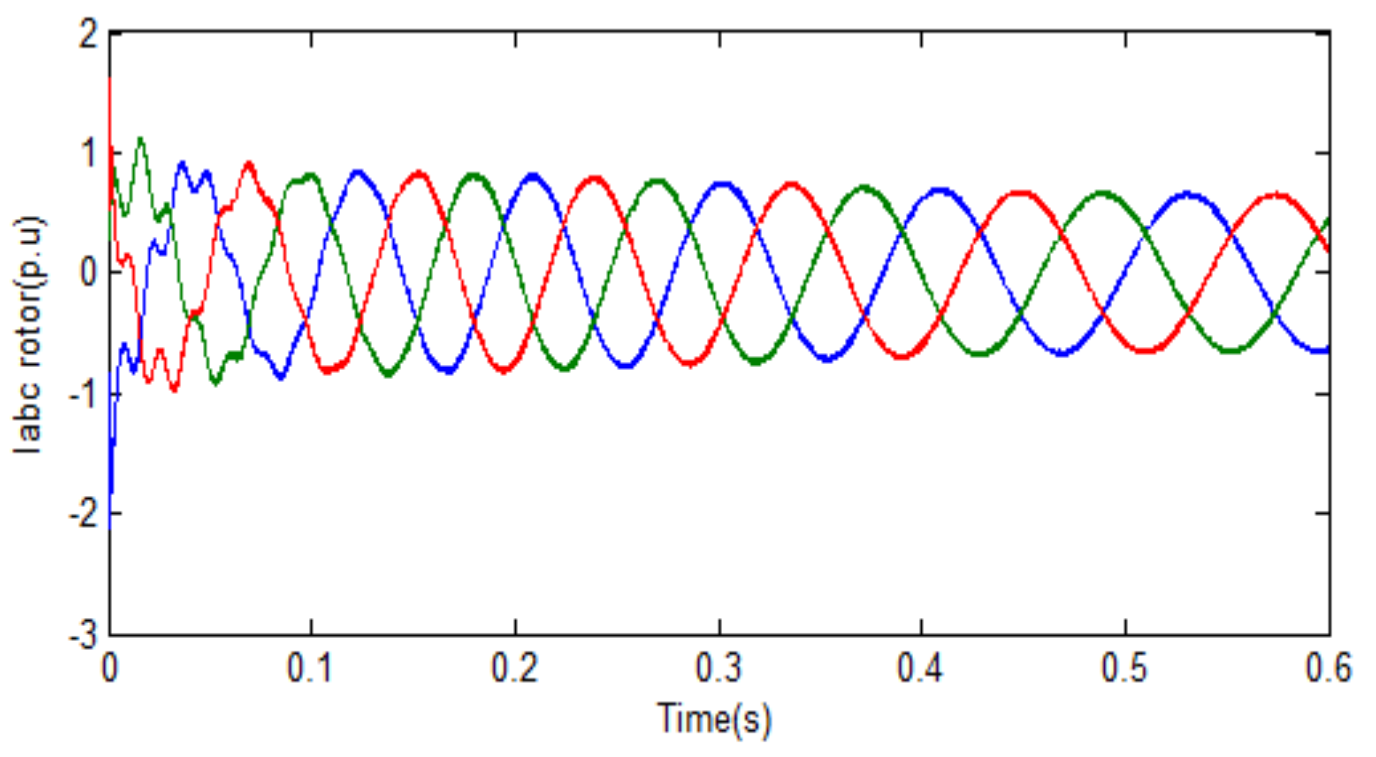

c) $I_{a b c}$ Rotor 


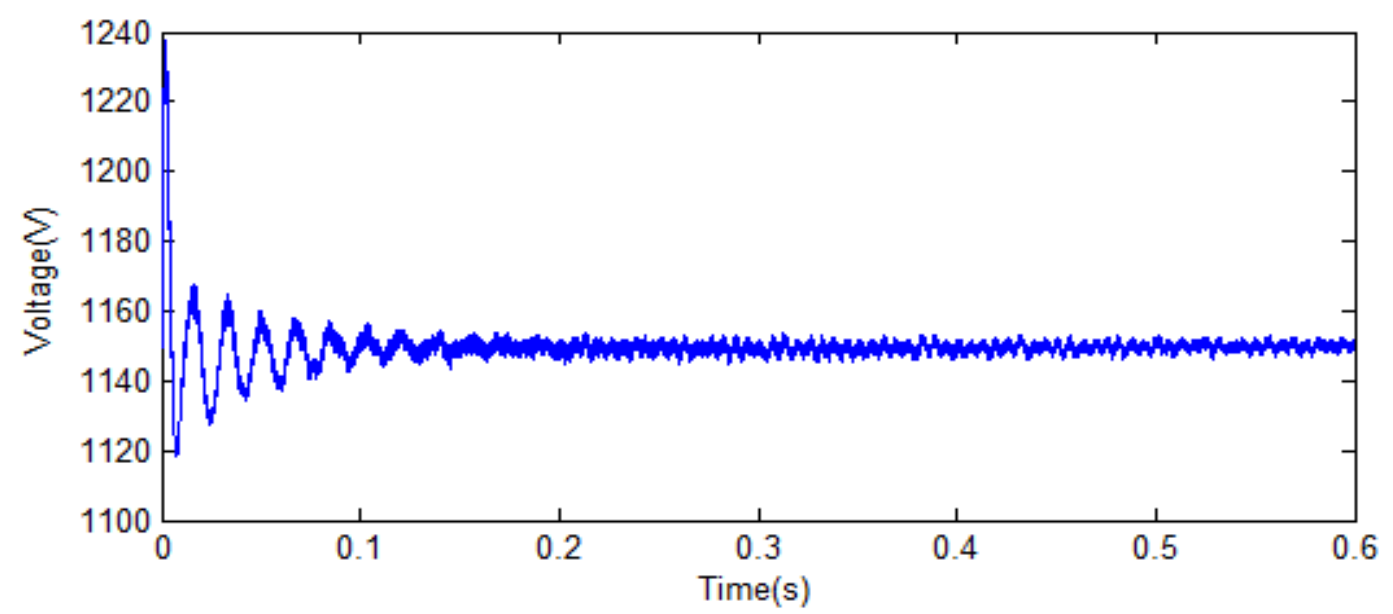

d) DC link Voltage

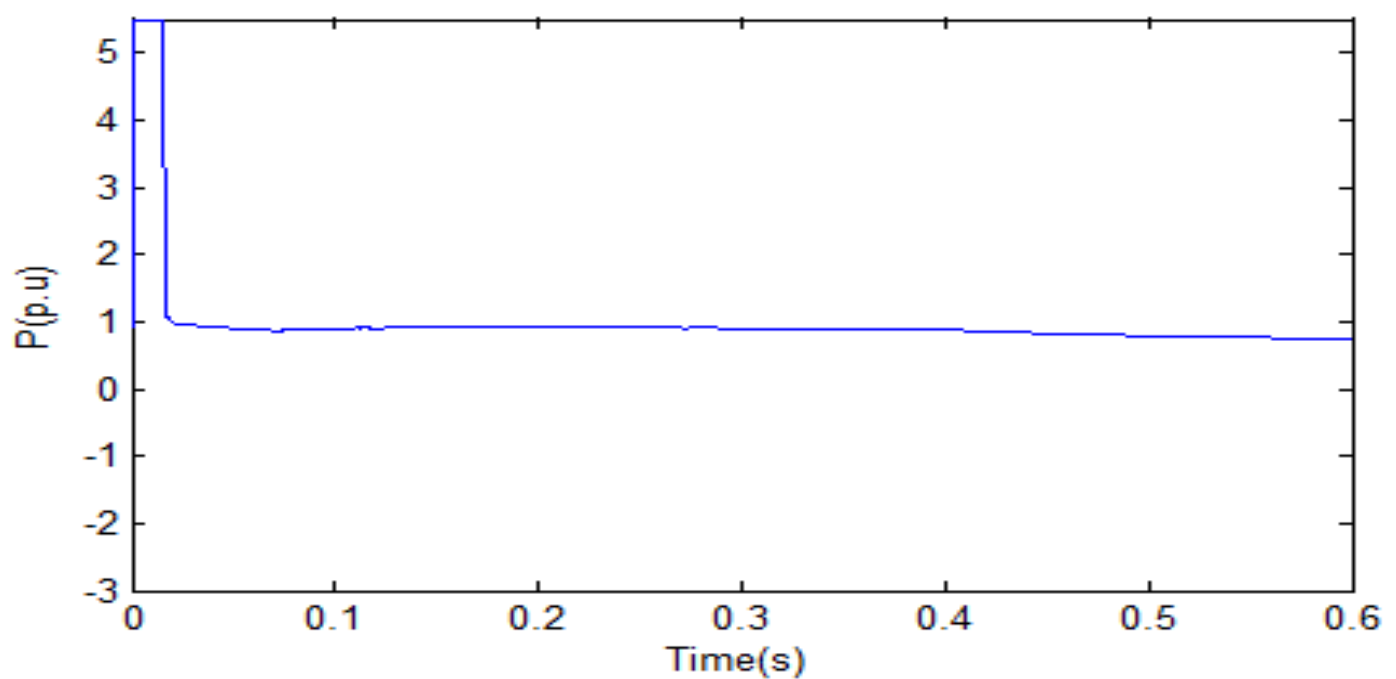

e) Active Power

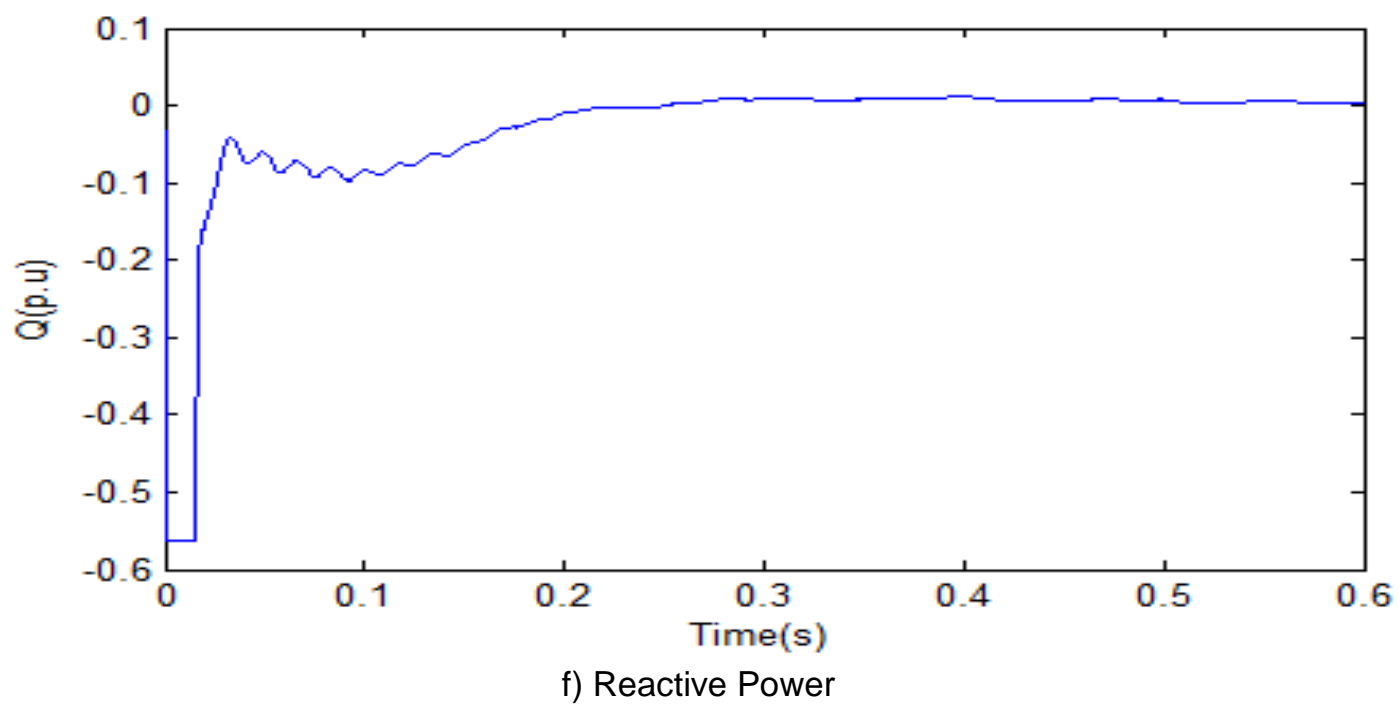




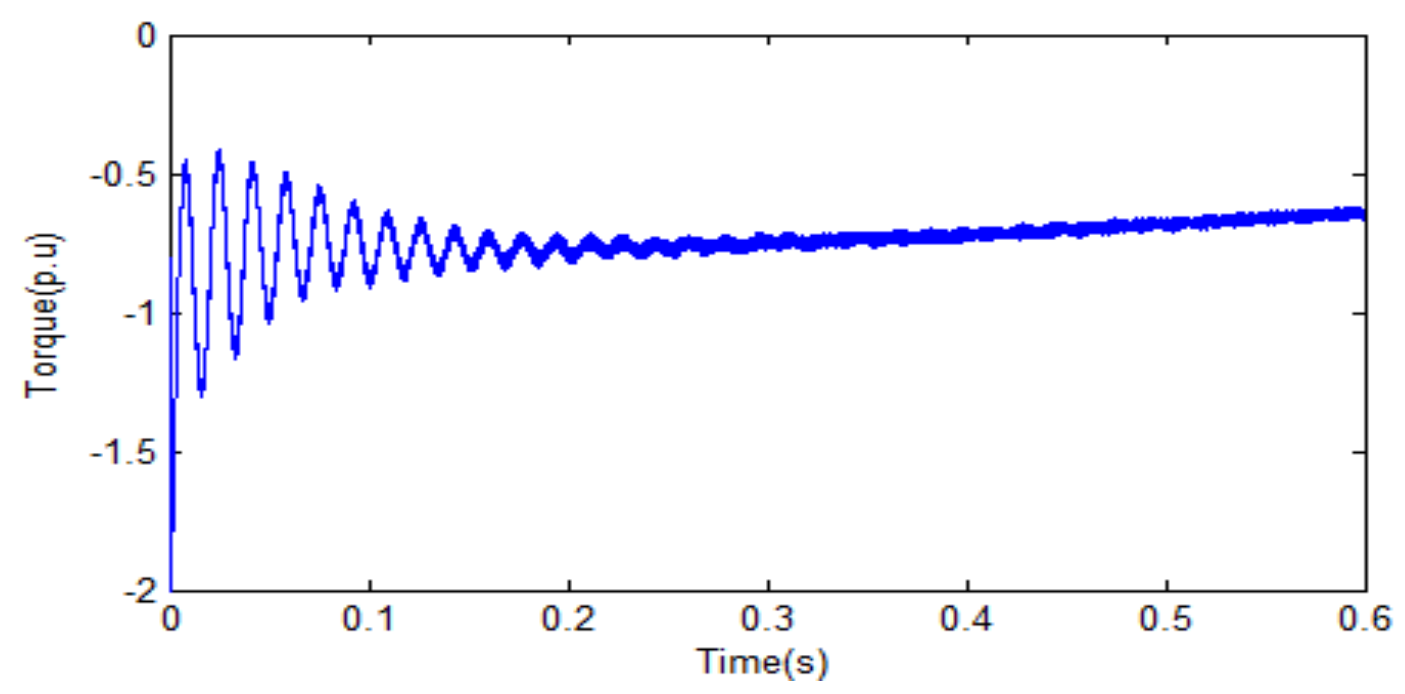

g) Electromagnetic Torque

Case (II) If the system is subjected to $30 \%$ dip from time $0.2 \mathrm{~s}$ to $0.4 \mathrm{~s}$

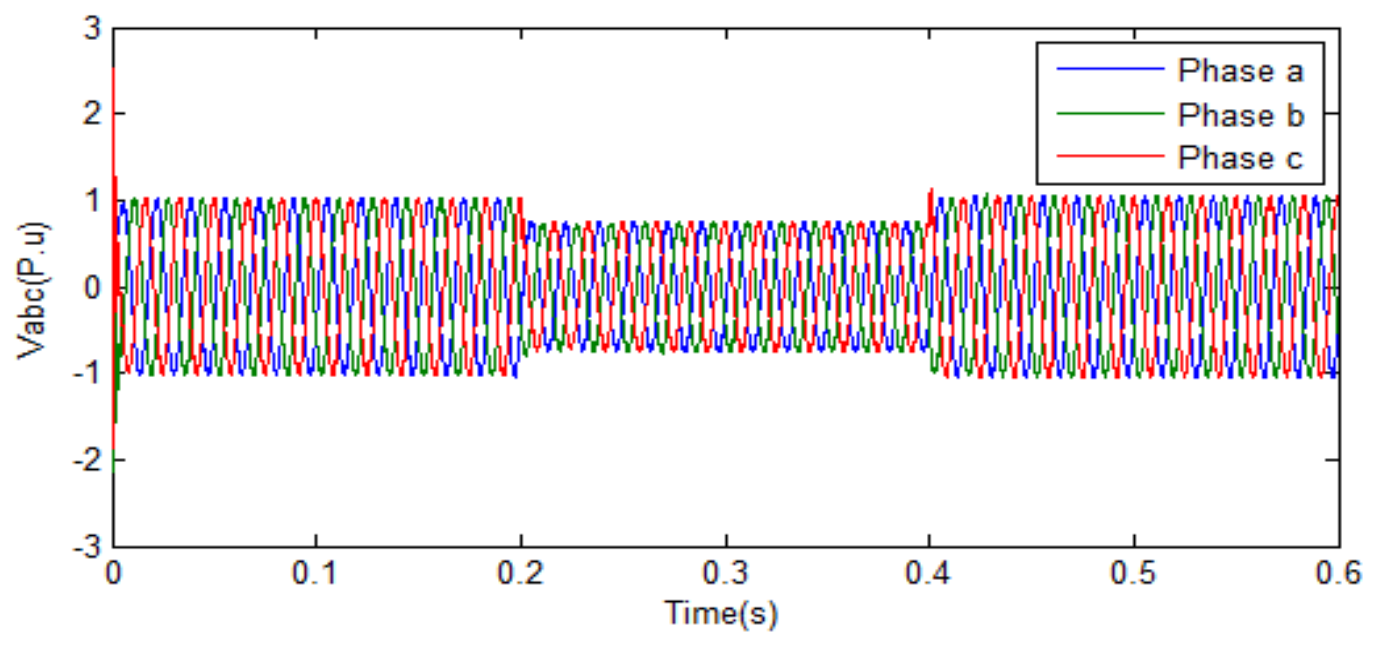

a) $V_{a b c}$ Stator

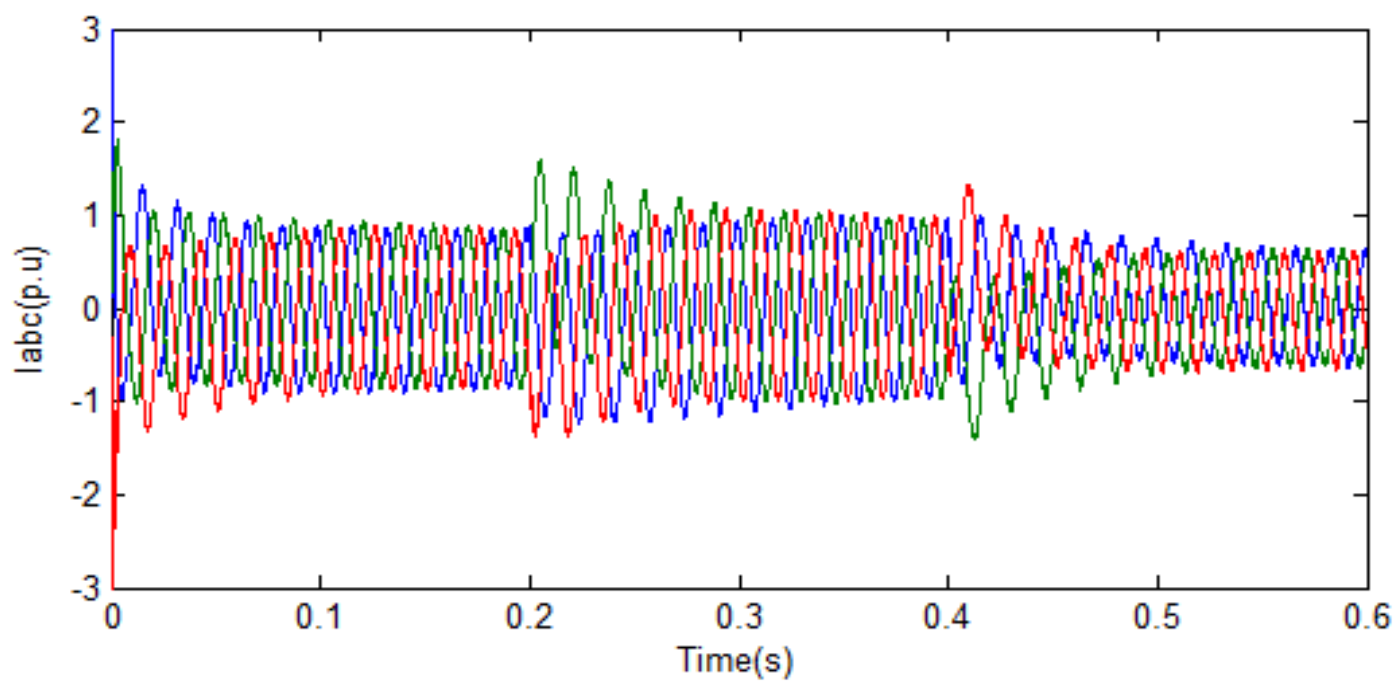


b) $I_{a b c}$ Stator

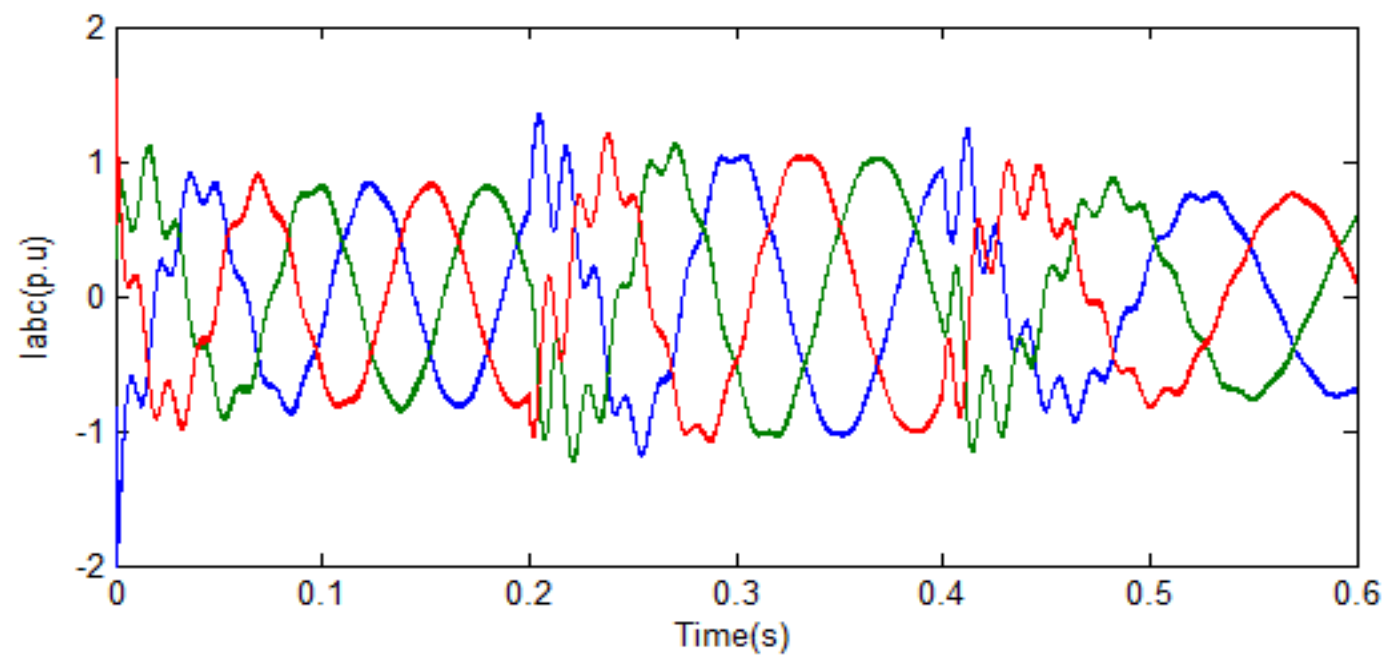

c) $I_{a b c}$ Rotor

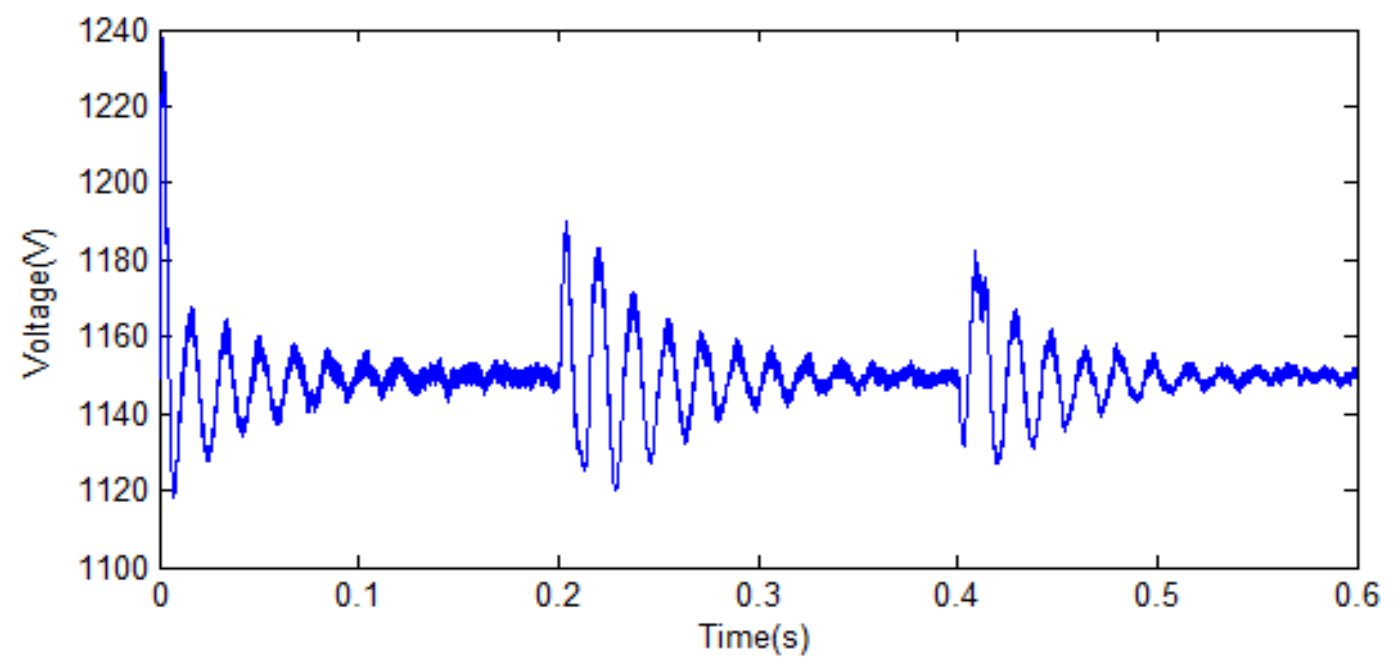

d) DC link Voltage

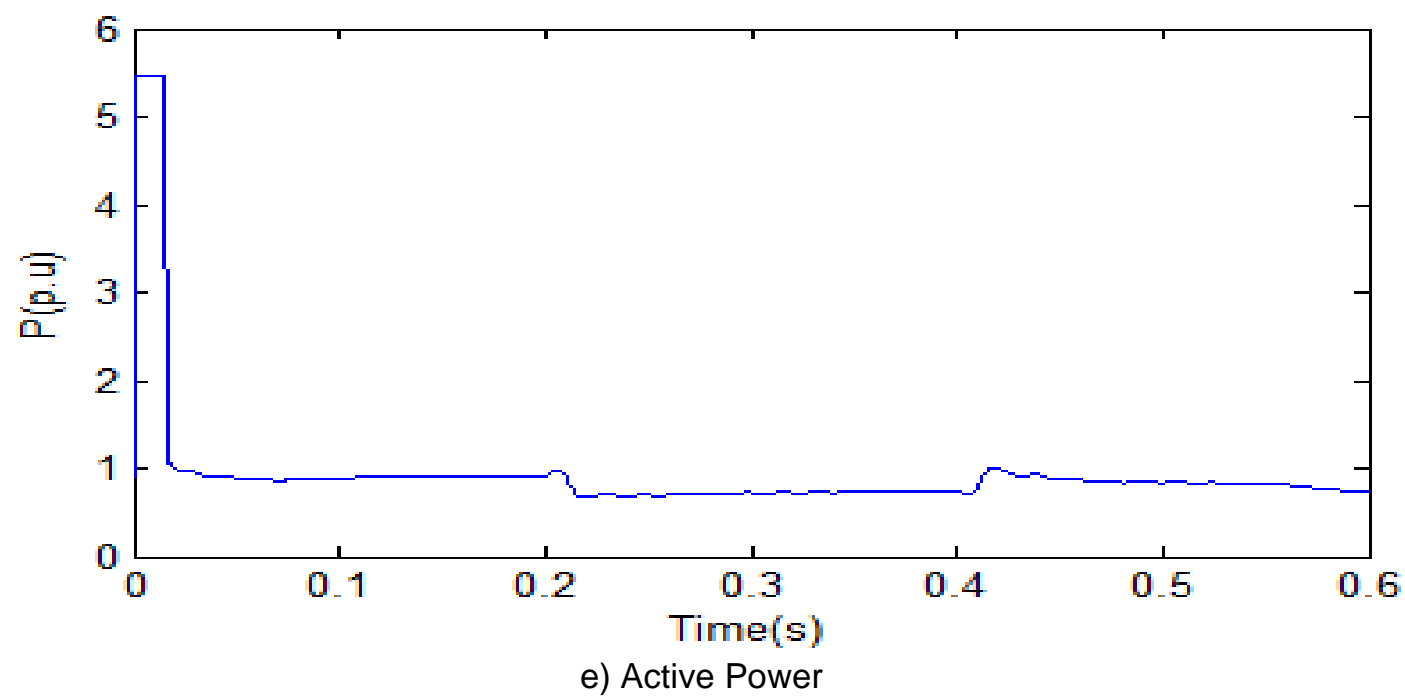



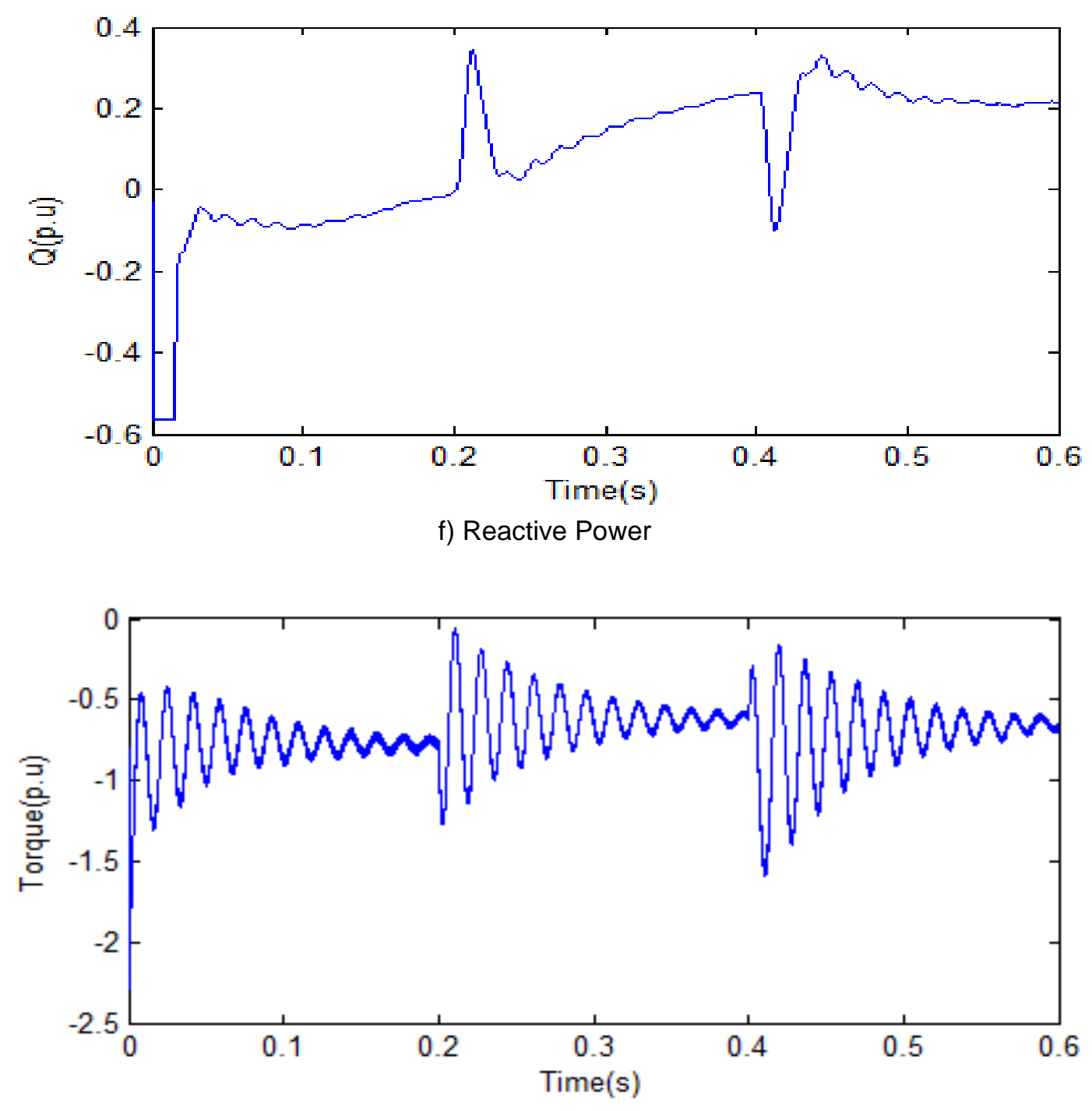

g) Electromagnetic Torque

\section{Conclusion}

This paper presents Steady State Analysis of Wind Turbine Using DFIG when subjected to different voltage sags at Grid. The Steady state behavior of DFIG is simulated using MATLAB/SIMULINK. When the voltage at grid is decreased by $30 \%$ from time $0.2 \mathrm{~s}$ to $0.4 \mathrm{~s}$, transients occur in rotor currents, stator voltage, DC link voltage, active power and reactive power, but they remain in acceptable range and the system recovers after the fault is removed.

\section{References}

[1] H. Sun, Y. Ren and H. Li, "DFIG wind power generation based on back-to-back PWM converter", in IEEE Proceedings, (2009).

[2] L. X, P. Cartwright, "Direct active and reactive power control of DFIG for wind energy generation", (2006).

[3] J. Cidrs Feijo and C. Carrillo, "Third order model for the doubly-fed induction machine", Elect. Power Syst. Res, vol. 56, (2000) March, pp. 121-127. 
[4] J. Vineela, G. Praneetha, R. Harshad, K. Masrunnisa, M. Pruthvi Kumar and T. Sandeep, “A Complete Analysis of Tolerance of Component in Analog VLSI Circuits Using Sensitivity", International Journal of Hybrid Information Technology, vol. 9, no. 7, (2016), pp. 9-18.

[5] S. Thakur and N. Kumar, "Design and Analysis of Multi Input Logic Gates Based on Quantum Dot Cellular Automata", IJRECE, vol. 3, no. 3, (2015), pp. 70-73.

[6] T. Ghennam, E. M. Berkouk and B. Francois, "DC-link voltage banlancing algorithm using a spacevector hysteresis current control for three-level VSI applied for wind conversion system," in Power Elect. and Appl., Sept. 2007.

[7] Y. Lei, A. Mullane and G. Lightbody, "Modeling of the wind turbine with a doubly fed induction generator for grid integration studies," IEEE Trans. on Energy Conversion, vol. 21, pp. 257-264, Mar. 2006.

[8] M. Stiebler, Wind Energy Systems for Electric Power Generation, springer, 2008.

[9] N. W. Miller, W. W. Price and J. J. Sanchez-Gasc, Dynamic modeling of GE 1.5 and 3.6 wind turbinegenerators, GE Power Systems, Oct. 2003..

[10] Thakur, Sandeep. "A Complete Analysis of Channel Estimation and Peak to Average Power Ratio in Wireless Communication Using Discrete Fourier Transform." International Journal of Future Generation Communication and Networking 9, no. 1 (2016): 107-114.

[11] R. Ganon, G. Sybille and S. Bernard, "Modeling and realtime simulation of a doubly-fed induction generator driven by a wind turbine," in Int. Conf. Power Systems Transients, June 2005. 